\title{
sRAGE in diabetic and non-diabetic critically ill patients: effects of intensive insulin therapy
}

Yaseen M Arabi ${ }^{1,2^{*}}$, Mohammed Dehbi ${ }^{3}$, Asgar H Rishu ${ }^{2}$, Engin Baturcam³ ${ }^{3}$ Salim H Kahoul ${ }^{2}$, Riette J Brits ${ }^{2}$, Brintha Naidu ${ }^{2}$ and Abderrezak Bouchama ${ }^{2,4}$

\begin{abstract}
Introduction: Hyperglycemia represents an independent prognostic factor in critically ill non-diabetic patients but not in those with diabetes. In this context, there is an ongoing debate on the benefit of an intensive insulin therapy, particularly in diabetic patients. We tested the hypothesis that expression of the receptor for advanced glycation end-products (RAGE), an important signal transduction receptor that elicits long-lasting nuclear factor kappa B (NF- $\kappa \mathrm{B}$ ) activation, may underlie this difference. RAGE expression is regulated by multiple ligands, including high mobility group box-1 (HMGB-1), and is reflected by its released soluble form (SRAGE).

Methods: A predesigned analysis was conducted of prospectively collected samples from 76 hyperglycemic critically ill patients (33 type-2 diabetes, 43 non-diabetes) aged $\geq 18$ years with blood glucose of $>6.1 \mathrm{mmol} / \mathrm{L}$ enrolled in a randomized controlled trial comparing intensive insulin therapy with conventional insulin therapy. sRAGE and its ligand HMGB-1 together with IL-6, and soluble thrombomodulin (as markers of inflammation and endothelial cell injury, respectively) were evaluated in ICU, at Days 1, 3, 5 and 7. Plasma samples from 18 healthy subjects were used as controls.

Results: Both diabetic and non-diabetic hyperglycemic patients showed increased plasma SRAGE, HMGB-1 and soluble thrombomodulin levels at the time of admission to ICU. Plasma IL-6 concentration was only increased in non-diabetic patients. Plasma levels of sRAGE were higher in diabetic compared with non-diabetic patients. Intensive insulin therapy resulted in a significant decrease of SRAGE and thrombomodulin at Day 7, in diabetic but not in non-diabetic patients. Circulating SRAGE levels correlated positively with IL-6 and soluble thrombomodulin levels and inversely with HMGB-1. Multivariate regression analysis demonstrated that sRAGE remains independently correlated with HMGB-1 only in diabetic patients. Neither SRAGE nor any inflammatory markers are associated with mortality.

Conclusions: These findings support the hypothesis that sRAGE release, time-course and response to intensive insulin therapy differ between hyperglycemic diabetic and non-diabetic critically ill patients. Whether this difference underlies the dissimilarity in clinical outcome of hyperglycemia in these two conditions warrants further studies.
\end{abstract}

\section{Introduction}

Hyperglycemia represents an important independent risk factor for morbidity and mortality in critically ill patients admitted to ICU [1,2]. Accordingly, the benefit of strict control of blood sugar with intensive insulin therapy (IIT) versus conventional insulin therapy (CIT) has been greatly debated with some studies revealing benefit and others lack of benefit [3-6]. Moreover, the

\footnotetext{
* Correspondence: yaseenarabi@yahoo.com

'College of Medicine, King Saud bin Abdulaziz University for Health Sciences, Riyadh, 11426, Saudi Arabia

Full list of author information is available at the end of the article
}

morbid consequences of hyperglycemia in critically ill patients, and the clinical effects of IIT, have been shown to differ according to diagnostic category [1-6]. In contrast to non-diabetic, hyperglycemia in ICU patients with type-2 diabetes is not independently associated with outcome, thus the benefit of IIT in this subpopulation remains unclear $[1,2]$.

Hyperglycemia in the presence of oxidant stress promotes glycoxidation of intra- and extracellular proteins and an accumulation of advanced glycation end-products (AGE) [7]. Engagement of AGE with their receptor RAGE (a member of the immunoglobulin

\section{Biomed Central}


superfamily of cell-surface molecules), elicits activation of the transcription factor nuclear factor kappa B (NF$\kappa \mathrm{B})$, expression of pro-inflammatory cytokines and induction of oxidative stress $[7,8]$. The RAGE-mediated inflammatory response has been implicated in microand macrovascular injury in diabetes $[9,10]$. Recent studies suggest that the pathogenic role of RAGE is not limited to diabetes but includes pathophysiological conditions characterized by excessive inflammatory response, such as sepsis and septic shock, acute lung injury, and intestinal dysfunction complicating hemorrhagic shock [11-17].

RAGE is activated by a large number of ligands including AGE, amyloid $\beta$-peptides, S- 100 proteins and HMGB-1 [7]. Preventing ligand-RAGE interaction by the administration of recombinant soluble RAGE attenuated intestinal dysfunction in mouse models of resuscitated hemorrhagic shock and lipopolysaccharide (LPS)-induced lung injury [12,18]. RAGE knockout mice were shown to be resistant to septic shock induced by cecal ligation and puncture $[11,16]$. These observations suggest that the RAGE pathway is part of the systemic inflammatory response in critical illnesses and play a pathogenic role. Because the level of RAGE expression is regulated by the presence of its ligands, such as AGE, that are known to accumulate at a greater rate for a longer time in diabetic compared with non-diabetic patients, we hypothesized that the RAGE pathway may underlie the difference in the clinical effects of hyperglycemia as well as response to IIT between diabetic and non-diabetic patients admitted to ICU [19].

RAGE has several soluble receptor isoforms resulting from alternative splicing of the full length mRNA or proteolysis of the cell-surface receptor [20,21]. An increased circulating total pool of sRAGE reflects enhanced tissue expression of RAGE in type 2-diabetic and non-diabetic subjects [22,23]. Hence, using an assay that measures the extracellular domain of sRAGE, we examined whether there is differential release of plasma sRAGE between hyperglycemic diabetic and non-diabetic critically ill patients admitted to ICU. Furthermore, the effects of conventional and intensive insulin therapy on the time course of sRAGE expression and the release of HMGB-1, thrombomodulin, and IL-6 were evaluated.

\section{Materials and methods Study population}

The present investigation included 76 hyperglycemic critically ill (33 type- 2 diabetes, 43 non-diabetes) consecutive patients who stayed at least three days in the ICU. Diagnosis of diabetes was based on the history as established by the patient primary team prior to hospital admission. The study population was part of a randomized controlled study that evaluated the effects of IIT versus CIT on the outcome of 523 critically ill patients. Informed consent was obtained from all patients included in the study before randomization. Insulin therapy was titrated to maintain blood glucose concentrations between 4.4 and $6.1 \mathrm{mmol} / \mathrm{L}$ in the IIT group and 10 and $11.1 \mathrm{mmol} / \mathrm{L}$ in the CIT group [6]. Patients were eligible in the original study, if they were $\geq 18$ years and were hyperglycemic (blood glucose of $>6.1 \mathrm{mmol} / \mathrm{L}$ during the first 24 hours of ICU admission). They were not included if they had type I diabetes, diabetic ketoacidosis, documented hypoglycemia on ICU admission or in the same hospitalization, brain death, do-not-resuscitate status, terminal illness defined as expected survival of less than four weeks as judged by the treating physician, post cardiac arrest, seizures within past six months, pregnancy, liver transplantation, burn victims, readmission to ICU within the same hospitalization, expected ICU length of stay (LOS) of $<24$ hrs, inability to obtain consent within the randomization window of 24 hrs of ICU admission, and enrollment in a competing trial, as published elsewhere [6]. The frequency of blood glucose monitoring was once hourly and was increased to every 20 minutes when blood glucose levels decreased to $\leq 3.2$ $\mathrm{mmol} / \mathrm{L}$, then was reduced to every two to four hours when measurements were at the target level. The study was approved by the Institutional Review Board of the King Abdulaziz Medical City.

\section{Blood sampling}

Blood samples were collected in EDTA-treated tubes on the day of admission to ICU, then on Days 3, 5 and 7. The samples were immediately centrifuged at $4^{\circ} \mathrm{C}$ for 20 minutes at $1,600 \mathrm{~g}$. Plasma samples were stored at $-80^{\circ} \mathrm{C}$ until assayed.

\section{Measurement of sRAGE, HMGB-1, thrombomodulin and IL-6 plasma levels}

Plasma concentrations of sRAGE, HMGB-1, thrombomodulin and IL- 6 were measured in accordance with the manufacturers' instructions using commercial ELISA kits from R\&D Systems (Minneapolis, MN, USA (Quantikine human IL-6 and sRAGE)), Diagnostica Stago (Asnieres, France (Asserachrom thrombomodulin)) and Shino-test Corporation (Tokyo, Japan (HMGB-1)). Eighteen plasma samples from healthy individuals were included in the sRAGE, HMGB-1, thrombomodulin and IL-6 assays.

\section{Statistical analysis}

Descriptive variables are given as the mean \pm SE. Skewed data are presented as median and interquartile ranges (IQR 25th to 75th percentile). Comparisons were performed using Wilcoxon and Kruskal-Wallis tests. The mixed linear model was used to compare the 
groups over time. Pearson correlation coefficients were used to determine the degree of the linear relationship between the continuous variables. Linear and logistic regression analyses were performed to determine the associations between outcome, inflammatory markers and clinical and biochemical variables. A multivariate linear regression model was used to test the interaction between renal function assessed by the calculated creatinine clearance and diabetes on plasma sRAGE levels. Differences were considered significant at $P<0.05$. The statistical analysis of data was done by using the statistical software package SAS version 9.1.3 (Statistical Analysis System, SAS Institute Inc., Cary, NC, USA).

\section{Results}

\section{Clinical characteristics of the study population}

Table 1 shows that diabetic patients are significantly older, with higher body mass index, blood sugar concentration and severity of illness and lower creatinine clearance on admission than non-diabetics. Hospital (but not ICU) mortality is also significantly higher in diabetic than non-diabetic patients. However, the present study was not powered to evaluate clinical outcomes.

\section{Circulating levels sRAGE, HMGB-1, thrombomodulin and} IL-6 in study population

On the day of admission to ICU, plasma sRAGE, HMGB-1 and thrombomodulin levels are significantly higher in all critically ill patients with or without diabetes as compared with healthy control subjects (Figure 1). Plasma IL-6 levels are significantly higher in non-diabetic but not in diabetic patients as compared with values from healthy control (Figure 1).

\section{Circulating levels SRAGE, HMGB-1, thrombomodulin and IL-6 in diabetic and non-diabetic patients}

Figure 1 shows that the plasma sRAGE concentration is significantly higher and IL-6 lower when diabetic patients are compared with those without diabetes (median (IQR) 2,406 (1,534 to 3,613 ) vs. 1,302 (918 to $2,260 \mathrm{pg} / \mathrm{ml}) ; P=0.003)$ and (61 (27 to 124$)$ vs. 159 (59 to $224 \mathrm{pg} / \mathrm{ml}$ ); $P=0.02$ ), respectively. No differences in HMGB-1 and soluble thrombomodulin is found between these two groups of patients. Plasma sRAGE levels correlate positively with plasma IL- 6 and soluble thrombomodulin levels and inversely with those of HMGB-1 (Figure 2).

\section{Effects of insulin therapy on SRAGE, HMGB-1, thrombomodulin and IL- 6 in diabetic and non-diabetic patients}

On the day of admission to ICU (day 1), the plasma levels of sRAGE, HMGB-1, thrombomodulin and IL-6 are similar between IIT and CIT in diabetic and nondiabetic patients (Figure 3). Compared with conventional insulin therapy, IIT does not influence the time course of sRAGE, HMGB-1, thrombomodulin and IL-6 in non-diabetic patients (Figure 3). However, in patients

Table 1 Baseline characteristics and outcome of diabetic and non-diabetic patients admitted in ICU

\begin{tabular}{|c|c|c|c|c|c|}
\hline & Diabetic & & Non-Diabetic & & \\
\hline & $\begin{array}{c}\text { IIT } \\
(n=16)\end{array}$ & $\begin{array}{c}\text { CIT } \\
(n=17)\end{array}$ & $\begin{array}{c}\text { IIT } \\
(n=27)\end{array}$ & $\begin{array}{c}\text { CIT } \\
(n=16)\end{array}$ & $P$ \\
\hline Age (years) & $66.1 \pm 3.5$ & $65.9 \pm 2.0$ & $49.3 \pm 4.5$ & $43.4 \pm 5.2$ & $<0.0001$ \\
\hline Sex, male: female & $6: 10$ & 7: 10 & $22: 5$ & $13: 3$ & 0.0001 \\
\hline BMI & $31.2 \pm 1.6$ & $33.8 \pm 2.6$ & $25.1 \pm 0.8$ & $26.6 \pm 1.0$ & 0.0003 \\
\hline APACHE II score & $28.6 \pm 1.9$ & $29.4 \pm 1.7$ & $22.3 \pm 1.6$ & $24.1 \pm 2.0$ & 0.001 \\
\hline Blood glucose (mmol/L) & $15.0 \pm 1.1$ & $13.4 \pm 0.9$ & $11.1 \pm 0.7$ & $10.0 \pm 0.4$ & $<.0001$ \\
\hline Creatinine $(\mu \mathrm{mol} / \mathrm{l})$ & $178 \pm 31$ & $222 \pm 47$ & $119 \pm 20$ & $144 \pm 41$ & 0.14 \\
\hline Creatinine clearance (ml/min) & $55 \pm 10$ & $52 \pm 9$ & $90 \pm 9$ & $95 \pm 15$ & 0.007 \\
\hline \multicolumn{6}{|l|}{ Admission category } \\
\hline Medical & 16 & 16 & 21 & 14 & 0.15 \\
\hline Surgical & 0 & 1 & 6 & 2 & 0.15 \\
\hline SOFA score (Day 1) & $9.3 \pm 0.7$ & $10.9 \pm 0.8$ & $8.3 \pm 0.6$ & $10.0 \pm 0.7$ & 0.11 \\
\hline $\begin{array}{l}\text { SOFA score (Day 3) } \\
\text { SEPSIS }\end{array}$ & $7.4 \pm 3.0$ & $8.6 \pm 3.7$ & $7.0 \pm 4.0$ & $8.9 \pm 2.6$ & 0.25 \\
\hline ICU acquired sepsis & 9 & 7 & 11 & 8 & 0.89 \\
\hline Length of hospital stay (days) & $64.4 \pm 14.4$ & $42.6 \pm 8.8$ & $48.4 \pm 10.0$ & $48.3 \pm 9.5$ & 0.77 \\
\hline ICU mortality, no. & 4 & 3 & 6 & 2 & 0.84 \\
\hline Hospital mortality, no. & 9 & 11 & 7 & 3 & 0.001 \\
\hline
\end{tabular}

Values represent mean (SE) in age, BMI, Acute Physiologic Score and Chronic Health Evaluation (APACHE II) score, blood glucose, and Sequential Organ Failure Assessment (SOFA) score on admission to ICU. P-values represent the comparison between diabetic $(n=33)$ and non-diabetic patients $(n=43)$. Creatinine clearance $=(140-\text { age }(\mathrm{yr}))^{*}$ weight $\left.(\mathrm{kg})\right) /(72 *$ serum $\mathrm{Cr}(\mathrm{mg} / \mathrm{dL}))$ (multiply by 0.85 for women) [34]. 

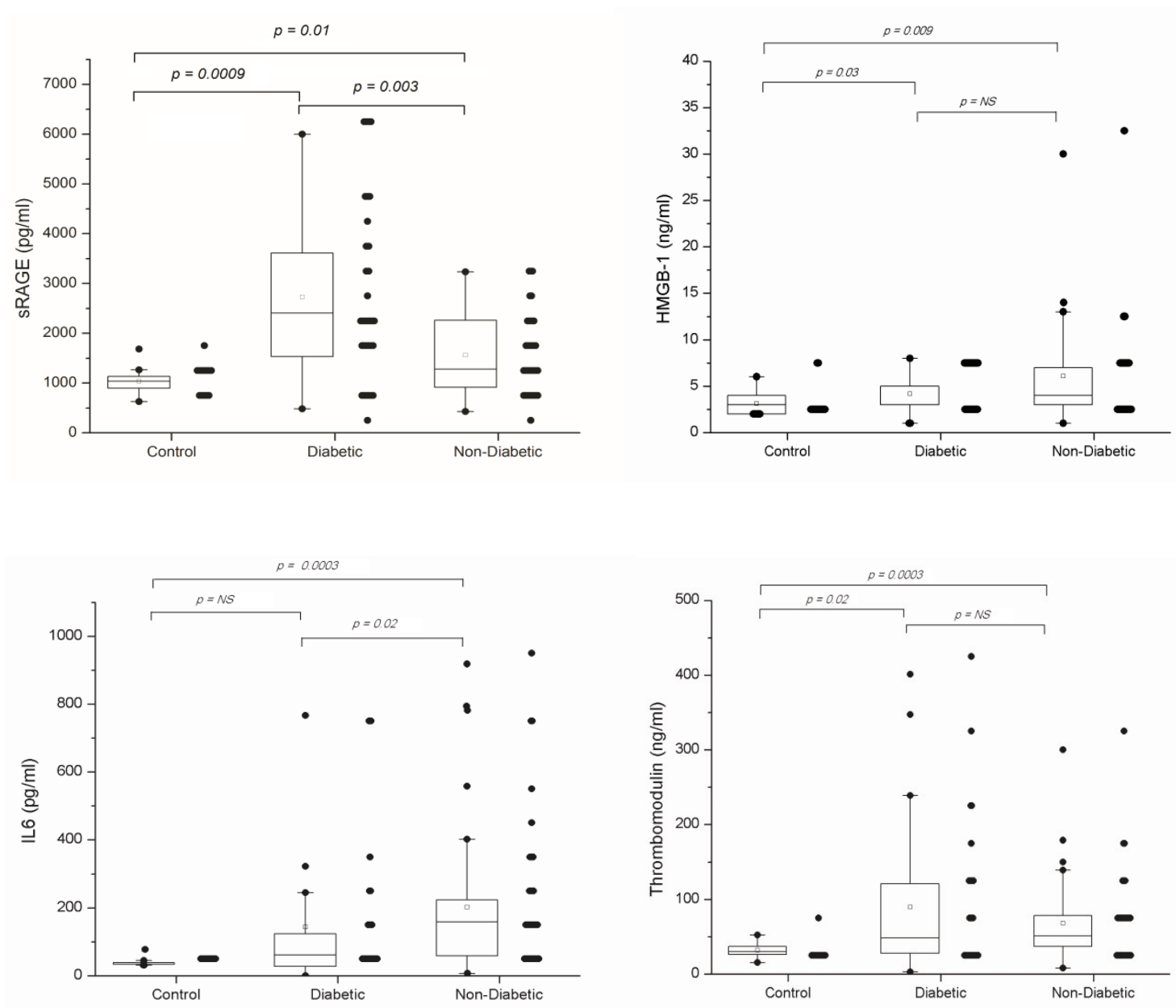

Figure 1 Plasma sRAGE, HMGB-1, thrombomodulin and IL-6 in diabetic and non-diabetics and control upon admission

with diabetes, IIT significantly decreases plasma sRAGE (903 (586 to 2,732$)$ vs. 2,684 ( 1,956 to 4,312$) \mathrm{pg} / \mathrm{ml}, P=$ 0.03 ) and thrombomodulin (61 (35 to 81$)$ vs. $104 \mathrm{ng} / \mathrm{ml}$, $P=0.03)$ at day 7 post-admission, while creatinine clearance did not significantly change over time (Figure 3 ).

\section{Interrelationship between SRAGE, biochemical markers} and outcome in diabetic and non-diabetic patients Multivariate regression analysis demonstrates that sRAGE remains independently correlated with HMGB-1 only in diabetic patients (Table 2). Neither levels of blood glucose and plasma creatinine, nor age, body mass index (BMI), Acute Physiology and Chronic Health Evaluation (APACHE) II score, creatinine clearance, and Sequential Organ Failure Assessment (SOFA) score are independently associated with sRAGE (Table 2). No significant interaction between the creatinine clearance and diabetes on plasma sRAGE levels was found $(P=0.08)$.

Uni- and multivariate logistic regression analyses demonstrate that hyperglycemia is an independent predictor of mortality in non-diabetic patients but not in patients with diabetes. Neither sRAGE nor any inflammatory markers are associated with mortality (Table 3). However, these findings should be interpreted cautiously due to the small sample size and the large heterogeneity of the study groups.

\section{Discussion}

Findings from this study reveal that on admission to ICU, critically ill patients with hyperglycemia display elevated circulating levels of sRAGE, HMGB-1 and soluble thrombomodulin. Circulating plasma IL-6 levels were increased only in non-diabetic patients. This suggest that sRAGE is a component of the host's systemic inflammatory response to hyperglycemic critical illness.

More important, the results show that diabetic and non-diabetic patients display distinct sRAGE release and time course pattern to acute illness as well as response to IIT. The plasma sRAGE concentration is significantly higher in diabetic patients than in those without 

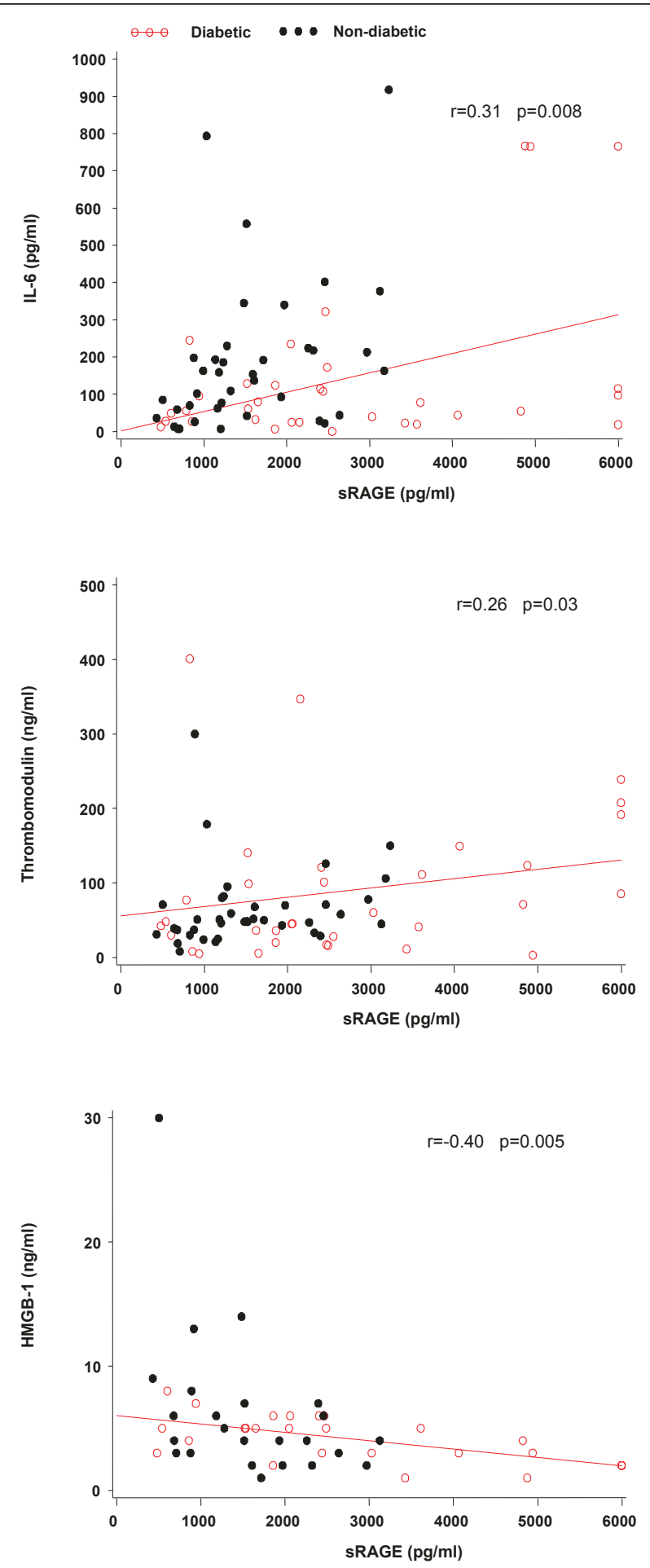

Figure 2 Correlation between plasma sRAGE, HMGB-1, soluble thrombomodulin and IL-6, respectively. $r$ represents the coefficient correlation.

diabetes. Administration of IIT attenuates significantly the levels of sRAGE at ICU day 7 only in diabetic patients. These findings suggest albeit indirectly that RAGE pathway activation and response to IIT differ between hyperglycemic diabetic and non-diabetic critically ill patients. Whether this accounts for the difference in clinical course and outcome observed between these two conditions could not be ascertained because 

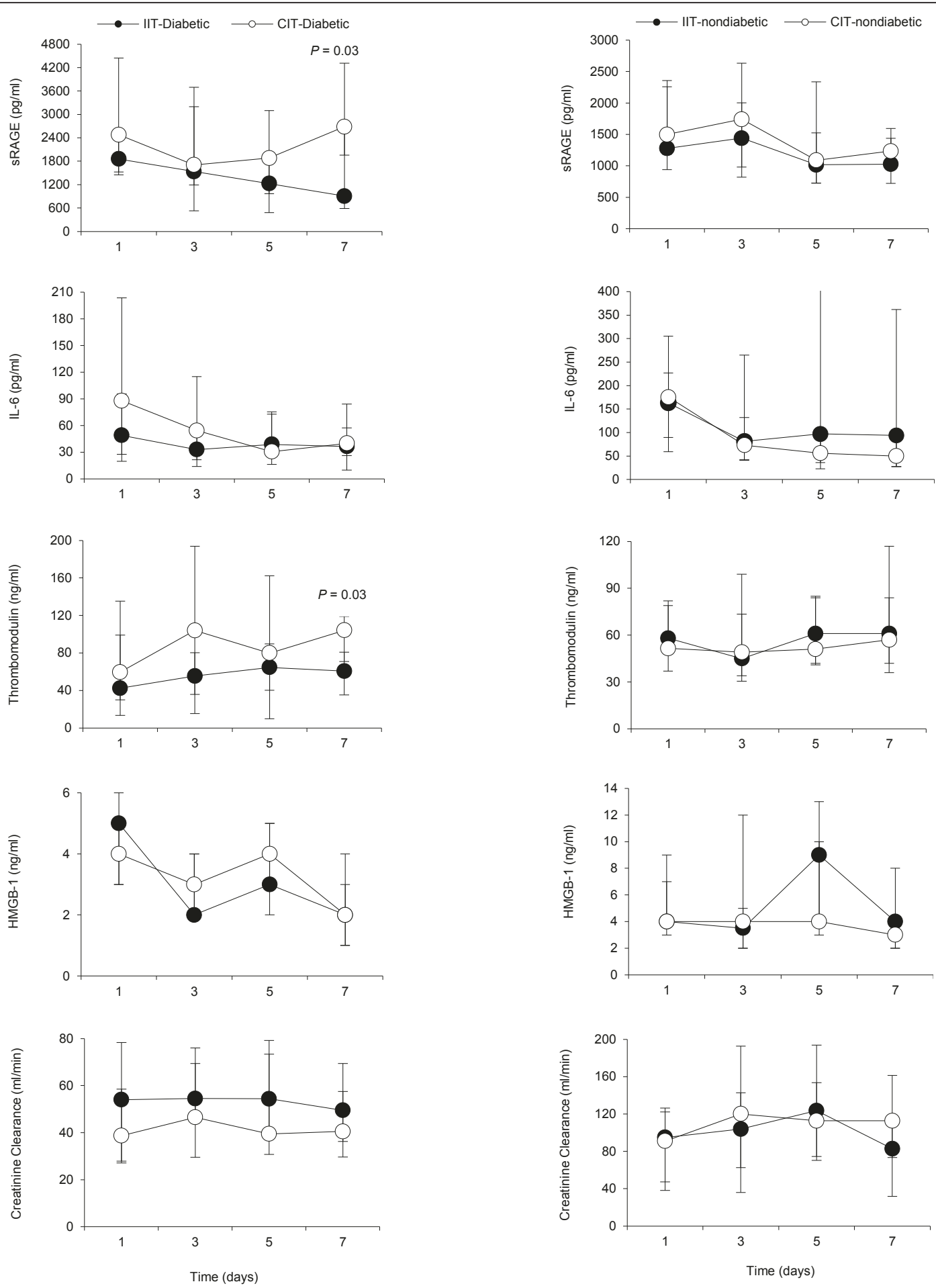

Figure 3 Effects of insulin therapy on SRAGE, IL-6, thrombomodulin, HMGB-1 and creatinine clearance in diabetic and non-diabetics.

of the discrepancy in baseline characteristics between the two study groups. Nonetheless, the findings warrant further investigations because of their potential clinical and therapeutic implications. Indeed, if different mechanistic pathways of inflammation are at play in hyperglycemic diabetic and non-diabetic critically ill patients, the use of a uniform therapeutic approach for all patients may not be physiologically sound. 
Table 2 Univariate and multivariate linear regression analyses of factors associated with sRAGE in diabetic and nondiabetics

\begin{tabular}{|c|c|c|c|c|c|c|c|c|}
\hline \multirow[b]{3}{*}{ Variable } & \multicolumn{4}{|c|}{ Diabetic } & \multicolumn{4}{|c|}{ Non-diabetic } \\
\hline & \multicolumn{2}{|c|}{ Univariate } & \multicolumn{2}{|c|}{ Multivariate } & \multicolumn{2}{|c|}{ Univariate } & \multicolumn{2}{|c|}{ Multivariate } \\
\hline & Estimate & $P$ & Estimate & $P$ & Estimate & $P$ & Estimate & $P$ \\
\hline Age (years) & -10.991 & NS & & & -4.456 & NS & & \\
\hline Gender & 769.540 & NS & & & 88.840 & NS & & \\
\hline BMl & -4.315 & NS & & & -42.630 & NS & & \\
\hline APACHE \| score & 89.353 & 0.03 & 63.82 & NS & 28.739 & NS & & \\
\hline SOFA score & 186.919 & NS & & & 60.331 & NS & & \\
\hline IL-6 (pg/ml) & 3.479 & 0.01 & 1.22 & NS & 1.486 & 0.01 & 1.68 & NS \\
\hline Thrombomodulin (ng/ml) & 4.165 & NS & & & 2.248 & NS & & \\
\hline HMGB-1 $(\mathrm{ng} / \mathrm{ml}) *$ & -544.690 & 0.001 & -509.97 & 0.002 & -56.697 & 0.03 & -49.56 & 0.059 \\
\hline Creatinine $(\mu \mathrm{mol} / \mathrm{l})$ & 1.834 & NS & & & 2.658 & 0.005 & 1.58 & NS \\
\hline Creatinine clearance (ml/minute) & -6.957 & NS & & & -2.999 & NS & & \\
\hline Blood glucose (mmol/L) & -37.363 & NS & & & -21.311 & NS & & \\
\hline $\mathrm{PaO}_{2} / \mathrm{FIO}_{2}(\mathrm{~mm} \mathrm{Hg})$ & 0.638 & NS & & & 1.066 & NS & & \\
\hline INR & 441.567 & NS & & & 16.071 & NS & & \\
\hline
\end{tabular}

* $P<0.05$ for both uni-and multivariate analysis

APACHE, Acute Physiologic Score and Chronic Health Evaluation; BMI, body mass index; HMGB-1, high mobility group box-1; IL-6, interleukin-6; INR, international normalized ratio; $\mathrm{PaO}_{2} / \mathrm{FIO}_{2}$, ratio of partial pressure of oxygen to the fraction of inspired oxygen; SOFA, Sequential Organ Failure Assessment.

RAGE is a pattern recognition receptor that has been shown to contribute to both initiation and perpetuation of inflammation in experimental sepsis $[7,11,12,14,16]$. In contrast to experimental studies, there is a paucity of clinical data [24-26]. In healthy human volunteers, LPS administration leads to increased plasma sRAGE levels [24]. In patients with sepsis or septic shock, plasma sRAGE was found elevated during the first 24 hours in
ICU, with the highest levels in non-survivors [26]. In another study, plasma sRAGE was associated with outcomes in patients with acute lung injury ventilated with higher tidal volumes [17]. Findings in the present study are in accordance with these reports by showing that sRAGE levels are elevated upon admission to ICU. It also extends them by demonstrating that the rise of plasma sRAGE levels remain sustained over a week and

Table 3 Univariate and multivariate logistic regression analysis of factors associated with mortality in diabetic and non-diabetics

\begin{tabular}{|c|c|c|c|c|c|c|c|c|}
\hline \multirow[b]{3}{*}{ Variable } & \multicolumn{4}{|c|}{ Diabetic } & \multicolumn{4}{|c|}{ Non-diabetic } \\
\hline & \multicolumn{2}{|c|}{ Univariate } & \multicolumn{2}{|c|}{ Multivariate } & \multicolumn{2}{|c|}{ Univariate } & \multicolumn{2}{|c|}{ Multivariate } \\
\hline & Estimate & $P$ & Estimate & $P$ & Estimate & $P$ & Estimate & $P$ \\
\hline Age (years) & 0.012 & NS & & & 0.036 & 0.04 & & NS \\
\hline Gender & 0.464 & NS & & & 0.875 & NS & & \\
\hline BMl & -0.075 & NS & & & -0.083 & NS & & \\
\hline APACHE II score & 0.100 & NS & & & 0.124 & 0.02 & & NS \\
\hline SOFA score * & 0.345 & 0.02 & 0.357 & 0.03 & 0.009 & NS & & \\
\hline sRAGE (pg/ml) & 0.0004 & NS & & & -0.00008 & NS & & \\
\hline IL-6 (pg/ml) & 0.00003 & NS & & & 0.001 & NS & & \\
\hline Thrombomodulin (ng/ml) & 0.004 & NS & & & 0.007 & NS & & \\
\hline HMGB-1 (ng/ml) & -0.321 & NS & & & 0.046 & NS & & \\
\hline Creatinine $(\mu \mathrm{mol} / \mathrm{L})$ & -0.002 & NS & & & 0.003 & NS & & \\
\hline Creatinine clearance (ml/minute) & -0.0096 & NS & & & -0.028 & 0.01 & -0.058 & NS \\
\hline Blood glucose $(\mathrm{mmol} / \mathrm{L})^{*}$ & 0.196 & NS & & & 0.514 & 0.003 & & 0.03 \\
\hline $\mathrm{PaO}_{2} / \mathrm{FiO}_{2}(\mathrm{~mm} \mathrm{Hg})$ & 0.0009 & NS & & & -0.006 & NS & & \\
\hline INR * & 2.753 & 0.01 & 2.328 & 0.04 & 3.176 & 0.02 & & NS \\
\hline
\end{tabular}

* $P<0.05$ for both uni-and multivariate analysis

APACHE, Acute Physiologic Score and Chronic Health Evaluation; HMGB-1, high mobility group box-1; IL-6, interleukin-6; INR, international normalized ratio; PaO ${ }_{2} /$ $\mathrm{FIO}_{2}$, ratio of partial pressure of oxygen to the fraction of inspired oxygen; SOFA, Sequential Organ Failure Assessment; sRAGE, soluble receptor for advanced glycation end-products. 
are not independently associated with outcome. Whether these long-lasting levels of plasma sRAGE reflect persistent RAGE pathway activation and thereby contribute to the perpetuation of inflammation in critically ill patients merit further studies.

Several studies have examined the association between sRAGE levels and renal function, and revealed that sRAGE is independently associated with decreased glomerular filtration rate [27-29], although the mechanisms underlying this relationship are not well understood. Both increased plasma sRAGE levels merely due to reduced elimination by failing kidneys, as well as a result of RAGE up-regulation to protect against AGE-accumulation and induction of tissue damage have been postulated. Most of these studies were confined to elderly stable patients in chronic renal failure with or without diabetes [27-29]. More recently, in patients with severe traumatic injury, plasma levels of sRAGE were found to predict the development of acute renal failure [30]. Taken together, these observations have prompted us to examine the association between sRAGE levels and renal function in our patients and the extent to which it could explain the observed difference in plasma sRAGE levels between the diabetic and non-diabetic patients. Using a multivariate linear regression model, interaction of diabetes with renal function could not be demonstrated, which means that the difference in plasma sRAGE levels on admission between diabetic and nondiabetic patients could not be explained on the basis of difference in renal function. Although, this finding should be interpreted with caution due to the small sample size of our study population, it may suggest that circulating sRAGE levels in hyperglycemic critically ill diabetic and non-diabetic patients reflect RAGE up-regulation. Although, the cellular source and precise role of sRAGE in our patients remain unclear, sRAGE has been demonstrated to exert a protective effect by working as a decoy domain receptor averting ligands binding to RAGE and, thereby, preventing inflammatory injury $[7,31]$. In this context, we determined that plasma HMGB-1 levels, a RAGE-ligand, and plasma IL-6 levels as a marker of systemic inflammation were increased in our study population. Surprisingly, we found that although in more severe conditions on admission to ICU, several patients with diabetes displayed a subdued inflammatory response as assessed by circulating IL-6 levels compared with non-diabetic patients. This finding is intriguing because there are very scarce data on the systemic inflammatory response to critical illness in diabetic patients that result in ICU admission. Nonetheless, earlier study demonstrated that the basal production of IL- 6 and TNF- $\alpha$ in cultured diabetic blood was markedly depressed in comparison with non-diabetic samples [32]. The release of IL- 6 and TNF- $\alpha$ increased following stimulation with LPS, but IL-6 remained significantly lower in diabetic patients than in controls, thus lending support to our observation [32]. The findings in the present study also reveal that plasma sRAGE level is independently correlated with HMGB-1 in diabetic patients only. Hence, it is appealing to speculate that sRAGE may have fulfilled its function as decoy in binding HMGB-1 in diabetic patients. Whether this explains the attenuated inflammatory response in this condition is unclear and merits further study.

Previous study demonstrated that IIT protects the endothelium of critically ill patients by down-regulating iNOS gene expression; however, diabetic and non-diabetic patients were not segregated [33]. Indeed, the present findings agree with this observation by showing that both diabetic and non-diabetic critically ill patients exhibit endothelial cell activation/injury as reflected by increased levels of soluble thrombomodulin. The study also reveals that IIT accelerates the decline of soluble thrombomodulin levels, suggesting a comparable protective effect of the endothelium but only in diabetic patients. Further, the concomitant decrease of sRAGE with thrombomodulin raises a novel hypothesis that IIT attenuated endothelial injury via RAGE down-regulation in this subpopulation.

Some limitations of this study merit consideration. First, the 76 patients studied comprise a small subgroup from a total sample of 523 in the medial-surgical ICU. Considering the inclusion and exclusion criteria of the $\mathrm{RCT}$, the results may not be extended to all hyperglycemic critically ill patients whether they are diabetic or not. Second, the immunoassay used in this study discriminates neither the RAGE that results from cleavage of the cell-surface receptor nor the different sRAGE splice variants [20]. Indeed, sRAGE isoforms have been shown to vary among cell type, and to display different affinity for RAGE ligands [20]. In our study, the cellular source of sRAGE was unclear, thus, for future studies specific assays for each splice variant would be required for investigating the significance of sRAGE in clinical samples.

\section{Conclusions}

Despite the limitations, the current study has revealed that SRAGE release, time-course and response to IIT differ between hyperglycemic diabetic and non-diabetic critically ill patients. Whether this difference underlies in part the dissimilarity in the immune response and outcome to critical illness in these two conditions warrants further studies.

\section{Key messages}

- Both diabetic and non-diabetic hyperglycemic patients display increased plasma sRAGE, HMGB-1 
and soluble thrombomodulin levels at the time of ICU admission

- Plasma levels of sRAGE are higher in critically ill diabetic patients compared with hyperglycemic nondiabetic patients

- Intensive insulin therapy significantly decreases plasma sRAGE and soluble thrombomodulin in diabetic patients, but not in those without diabetes

- RAGE pathway activation and response to IIT differ between hyperglycemic diabetic and non-diabetic critically ill patients

\begin{abstract}
Abbreviations
AGE: advanced glycation end-products; APACHE II: Acute Physiology and Chronic Health Evaluation; BMI: body mass index; CIT: conventional insulin therapy; EDTA: ethylene diamine tetra acetic acid; HMGB-1: high mobility group box-1; IIT: intensive insulin therapy; IL-6: interleukin-6; iNOS: inducible form of nitric oxide synthase; IQR: interquartile range; LOS: length of stay; LPS: lipopolysaccharide; mRNA: messenger RNA; NF-KB: nuclear factor kappa B; RAGE: receptor for advanced glycation end-products; RCT: randomized controlled trial; SAS: Statistical Analysis System; SOFA: Sequential Organ Failure Assessment; TNF: tumor necrosis factor.
\end{abstract}

\section{Author details}

'College of Medicine, King Saud bin Abdulaziz University for Health Sciences, Riyadh, 11426, Saudi Arabia. ${ }^{2}$ Intensive Care Department, King Abdulaziz Medical City, Riyadh, 11426, Saudi Arabia. ${ }^{3}$ Department of Biomedical Research, Biochemistry \& Molecular Biology Unit, Dasman Diabetes Institute, 15462, Kuwait. ${ }^{4}$ Experimental Medicine Department, King Abdullah International Medical Research Center, Riyadh, 11426, Saudi Arabia.

\section{Authors' contributions}

The PI (YMA) had full access to all of the data in the study and takes responsibility for the integrity of the data and the accuracy of the data analysis. YMA, AHR and $A B$ were responsible for the conception and design. YMA, AHR, EB, SHK, RJB and BN took part in the acquisition of data. EB, SHK, $R J B$ and $B N$ were involved in blood sample collection. $A B, E B, S H K, R J B$ and $B N$ were involved in laboratory work. $Y M A, M D$ and $A B$ were responsible for analysis and interpretation of data. $Y M A, M D$ and $A B$ were responsible for drafting the manuscript. YMA, $A H R, E B$ and $A B$ were in charge for the critical revision of the manuscript. $Y M A, M D$ and $A B$ were responsible for statistical analysis. YMA, AHR and $A B$ were in charge for the general supervision.

\section{Competing interests}

The authors declare that they have no competing interests.

Received: 29 March 2011 Revised: 23 July 2011

Accepted: 26 August 2011 Published: 26 August 2011

\section{References}

1. Krinsley JS: Association between hyperglycemia and increased hospital mortality in a heterogeneous population of critically ill patients. Mayo Clin Proc 2003, 78:1471-1478.

2. Egi M, Bellomo R, Stachowski E, French CJ, Hart GK, Hegarty C, Bailey M: Blood glucose concentration and outcome of critical illness: the impact of diabetes. Crit Care Med 2008, 36:2249-2255.

3. Finfer S, Chittock DR, Su SY, Blair D, Foster D, Dhingra V, Bellomo R, Cook D, Dodek P, Henderson WR, Hebert PC, Heritier S, Heyland DK, McArthur C, McDonald E, Mitchell I, Myburgh JA, Norton R, Potter J, Robinson BG, Ronco JJ: Intensive versus conventional glucose control in critically ill patients. N Engl J Med 2009, 360:1283-1297.

4. Van den Berghe G, Wilmer A, Hermans G, Meersseman W, Wouters PJ, Milants I, Van Wijngaerden E, Bobbaers H, Bouillon R: Intensive insulin therapy in the medical ICU. N Engl J Med 2006, 354:449-461.

5. Van den Berghe G, Wouters P, Weekers F, Verwaest C, Bruyninckx F, Schetz M, Vlasselaers D, Ferdinande P, Lauwers P, Bouillon R: Intensive insulin therapy in the critically ill patients. N Engl J Med 2001, 345:1359-1367.

6. Arabi YM, Dabbagh OC, Tamim HM, Al-Shimemeri AA, Memish ZA, Haddad SH, Syed SJ, Giridhar HR, Rishu AH, Al-Daker MO, Kahoul SH, Britts RJ, Sakkijha MH: Intensive versus conventional insulin therapy: a randomized controlled trial in medical and surgical critically ill patients. Crit Care Med 2008, 36:3190-3197.

7. Schmidt AM, Yan SD, Yan SF, Stern DM: The multiligand receptor RAGE as a progression factor amplifying immune and inflammatory responses. $J$ Clin Invest 2001, 108:949-955.

8. Basta G, Lazzerini G, Massaro M, Simoncini T, Tanganelli P, Fu C, Kislinger T, Stern DM, Schmidt AM, De Caterina R: Advanced glycation end products activate endothelium through signal-transduction receptor RAGE: a mechanism for amplification of inflammatory responses. Circulation 2002, 105:816-822.

9. Yan SF, Ramasamy R, Naka Y, Schmidt AM: Glycation, inflammation, and RAGE: a scaffold for the macrovascular complications of diabetes and beyond. Circ Res 2003, 93:1159-1169.

10. Yan SF, Barile GR, D'Agati V, Du Yan S, Ramasamy R, Schmidt AM: The biology of RAGE and its ligands: uncovering mechanisms at the heart of diabetes and its complications. Curr Diab Rep 2007, 7:146-153.

11. Liliensiek B, Weigand MA, Bierhaus A, Nicklas W, Kasper M, Hofer S, Plachky J, Grone HJ, Kurschus FC, Schmidt AM, Yan SD, Martin E, Schleicher E, Stern DM, Hammerling GG, Nawroth PP, Arnold B: Receptor for advanced glycation end products (RAGE) regulates sepsis but not the adaptive immune response. J Clin Invest 2004, 113:1641-1650.

12. Raman KG, Sappington PL, Yang R, Levy RM, Prince JM, Liu S, Watkins SK, Schmidt AM, Billiar TR, Fink MP: The role of RAGE in the pathogenesis of intestinal barrier dysfunction after hemorrhagic shock. Am J Physiol Gastrointest Liver Physiol 2006, 291:G556-565.

13. Herold K, Moser B, Chen Y, Zeng S, Yan SF, Ramasamy R, Emond J, Clynes R, Schmidt AM: Receptor for advanced glycation end products (RAGE) in a dash to the rescue: inflammatory signals gone awry in the primal response to stress. J Leukoc Biol 2007, 82:204-212.

14. Clynes R, Herold K, Schmidt AM: RAGE: exacting a toll on the host in response to polymicrobial sepsis and Listeria monocytogenes. Crit Care 2007, 11:183.

15. Uchida T, Shirasawa M, Ware LB, Kojima K, Hata Y, Makita K, Mednick G, Matthay ZA, Matthay MA: Receptor for advanced glycation end-products is a marker of type I cell injury in acute lung injury. Am J Respir Crit Care Med 2006, 173:1008-1015.

16. Lutterloh EC, Opal SM, Pittman DD, Keith JC Jr, Tan XY, Clancy BM, Palmer H, Milarski K, Sun Y, Palardy JE, Parejo NA, Kessimian N: Inhibition of the RAGE products increases survival in experimental models of severe sepsis and systemic infection. Crit Care 2007, 11:R122.

17. Calfee CS, Ware LB, Eisner MD, Parsons PE, Thompson BT, Wickersham N, Matthay MA: Plasma receptor for advanced glycation end products and clinical outcomes in acute lung injury. Thorax 2008, 63:1083-1089.

18. Zhang H, Tasaka S, Shiraishi Y, Fukunaga K, Yamada W, Seki H, Ogawa Y, Miyamoto K, Nakano Y, Hasegawa N, Miyasho T, Maruyama I, Ishizaka A: Role of soluble receptor for advanced glycation end products on endotoxin-induced lung injury. Am J Respir Crit Care Med 2008, 178:356-362.

19. Nakamura K, Yamagishi SI, Matsui T, Adachi H, Takeuchi M, Imaizumi T: Serum levels of soluble form of receptor for advanced glycation end products (sRAGE) are correlated with AGEs in both diabetic and nondiabetic subjects. Clin Exp Med 2007, 7:188-190.

20. Hudson BI, Carter AM, Harja E, Kalea AZ, Arriero M, Yang H, Grant PJ, Schmidt AM: Identification, classification, and expression of RAGE gene splice variants. FASEB J 2008, 22:1572-1580.

21. Hanford LE, Enghild JJ, Valnickova Z, Petersen SV, Schaefer LM, Schaefer TM, Reinhart TA, Oury TD: Purification and characterization of mouse soluble receptor for advanced glycation end products (sRAGE). J Biol Chem 2004, 279:50019-50024.

22. Yamagishi S, Imaizumi T: Serum levels of soluble form of receptor for advanced glycation end products (sRAGE) may reflect tissue RAGE expression in diabetes. Arterioscler Thromb Vasc Biol 2007, 27:e32, author reply e33-34.

23. Nakamura $K$, Yamagishi $S$, Nakamura $Y$, Takenaka $K$, Matsui $T$, Jinnouchi $Y$, Imaizumi T: Telmisartan inhibits expression of a receptor for advanced glycation end products (RAGE) in angiotensin-II-exposed endothelial 
cells and decreases serum levels of soluble RAGE in patients with essential hypertension. Microvasc Res 2005, 70:137-141.

24. Soop A, Sunden-Cullberg J, Albert J, Hallstrom L, Treutiger CJ, Sollevi A: Adenosine infusion attenuates soluble RAGE in endotoxin-induced inflammation in human volunteers. Acta Physiol (Oxf) 2009, 197:47-53.

25. Briot R, Frank JA, Uchida T, Lee JW, Calfee CS, Matthay MA: Elevated levels of the receptor for advanced glycation end products, a marker of alveolar epithelial type I cell injury, predict impaired alveolar fluid clearance in isolated perfused human lungs. Chest 2009, 135:269-275.

26. Bopp C, Hofer S, Weitz J, Bierhaus A, Nawroth PP, Martin E, Buchler MW, Weigand MA: SRAGE is elevated in septic patients and associated with patients outcome. J Surg Res 2008, 147:79-83.

27. Kalousova M, Hodkova M, Kazderova M, Fialova J, Tesar V, DusilovaSulkova S, Zima T: Soluble receptor for advanced glycation end products in patients with decreased renal function. Am J Kidney Dis 2006, 47:406-411.

28. Semba RD, Ferrucci L, Fink JC, Sun K, Beck J, Dalal M, Guralnik JM, Fried LP: Advanced glycation end products and their circulating receptors and level of kidney function in older community-dwelling women. Am J Kidney Dis 2009, 53:51-58.

29. Hou FF, Ren H, Owen WF Jr, Guo ZJ, Chen PY, Schmidt AM, Miyata T, Zhang X: Enhanced expression of receptor for advanced glycation end products in chronic kidney disease. J Am Soc Nephrol 2004, 15:1889-1896.

30. Cohen MJ, Carles M, Brohi K, Calfee CS, Rahn P, Call MS, Chesebro BB, West MA, Pittet JF: Early release of soluble receptor for advanced glycation endproducts after severe trauma in humans. J Trauma 2010 68:1273-1278.

31. Park L, Raman KG, Lee KJ, Lu Y, Ferran LJ Jr, Chow WS, Stern D, Schmidt AM: Suppression of accelerated diabetic atherosclerosis by the soluble receptor for advanced glycation endproducts. Nat Med 1998, 4:1025-1031.

32. Pickup JC, Chusney GD, Thomas SM, Burt D: Plasma interleukin-6, tumour necrosis factor alpha and blood cytokine production in type 2 diabetes. Life Sci 2000, 67:291-300.

33. Langouche L, Vanhorebeek I, Vlasselaers D, Vander Perre S, Wouters PJ, Skogstrand K, Hansen TK, Van den Berghe G: Intensive insulin therapy protects the endothelium of critically ill patients. J Clin Invest 2005, 115:2277-2286.

34. Cockcroft DW, Gault MH: Prediction of creatinine clearance from serum creatinine. Nephron 1976, 16:31-41

doi:10.1186/cc10420

Cite this article as: Arabi et al:: SRAGE in diabetic and non-diabetic critically ill patients: effects of intensive insulin therapy. Critical Care 2011 15:R203.

\section{Submit your next manuscript to BioMed Central and take full advantage of:}

- Convenient online submission

- Thorough peer review

- No space constraints or color figure charges

- Immediate publication on acceptance

- Inclusion in PubMed, CAS, Scopus and Google Scholar

- Research which is freely available for redistribution 